\title{
Adverse Event Hospitalization Required Indicator
}

National Cancer Institute

\section{Source}

National Cancer Institute. Adverse Event Hospitalization Required Indicator. NCI

Thesaurus. Code C93713.

Specifies whether the subject requires hospitalization or prolong ation of existing hospitalization as a result of the adverse event. 